\title{
Otomobil sahipliğini etkileyen faktörlerin farklı regresyon modelleri ile incelenmesi
}

\section{Examining the different factors affecting automobile ownership with regression models}

\section{Şenol Çelik}

Doç. Dr., Bingöl Üniversitesi, Ziraat Fakültesi, Biyometri ve Genetik ABD, Bingöl, TÜRKIYYE, e-mail: senolcelik@bingol.edu.tr

Öz

Bu çalışma, nüfus, tüketici fiyat indeksi (TÜFE), karayolu uzunluğu, GSYİH ve dolar kuru değişkenleri kullanılarak kişi başına otomobil sahipliğini tahmin etmek amacıyla yapılmıştır. Bu amaçla, çalışmada kullanılan veri setine çoklu regresyon analizi uygulanmıştır. Yapılan analizde çoklu bağlantı sorunu olduğu görülmüştür. Bu sorunu gidermek için alternatif regresyon yöntemlerinden Ridge, Lasso ve Elastic-Net regresyon yöntemleri uygulanmıştır. Ridge, Lasso ve Elastic-Net regresyon yöntemleri için belirleme katsayıları sırasıyla 0.953, 0.976 ve 0.952 ; düzeltilmiş belirleme katsayıları sırasıyla 0.932, 0.972 ve 0.943 bulunmuştur. Aynı yöntemler için hata kareler ortalamaları sırasıyla 6.044, 4.461 ve 4.655 bulunmuştur. Elde edilen bu sonuçlara göre, alternatif modellerinden en küçük hata kareler ortalaması ve en büyük belirleme katsayısına sahip Lasso regresyon yönteminin en uygun yöntem olduğu görülmüştür.

Anahtar kelimeler: Çoklu bağlantı, en küçük kareler, Ridge, Lasso, Elastic-Net

\footnotetext{
Abstract

The aim of the study is to estimate the ownership of automobiles per capita using variables such as population, Consumer Price Index (CPI), road length, GDP, and exchange rate of the dollar. For that purpose, multiple regression analysis is applied on the data set in this study. It was found that a multicollinearity problem has occurred in the analysis performed. Regression methods from alternative regression methods such as Ridge, Lasso, and Elastic-Net are used to solve this problem. It has been found that the coefficient of determination for Ridge, Lasso, and Elastic-Net regression methods are $0.953,0.976$, and 0.952 , respectively; adjusted coefficients of determination are $0.932,0.972$, and 0.943 , respectively. The 
mean squared errors for the same methods are found to be $6.044,4.461$, and 4.655 , respectively. According to the results obtained, it is seen that the Lasso regression method is the most suitable method with the smallest mean squared error and the largest coefficient of determination from the alternative models.

Keywords: Multicollinearity, least squares, Ridge, Lasso, Elastic-Net

\section{GİRİş}

Kara yolu ulaşımında ilk akla gelen ulaşım aracı olan otomobiller, ilk imal edildiğinden günümüze kadar teknolojinin de gelişmesiyle beraber günden güne evrim geçirmiş, insanlar arasında en önemli ulaşım aracı olmuştur. Otomobil, sağladığı yoğun teknolojik donanımlarla bireylerin hem taşıma ihtiyacını gidermiş hem de bireyler için bir tutku olmuştur (Yayar ve ark., 2015).

Otomobil insanların gerek günlük kullanımı, gerekse dinlenme, eğlenme ve gezi gibi ihtiyaçlarını da karşılamaktadır. Tüketiciler otomobil satın alarak maddi ihtiyaçlarının yanında, çeşitli psikolojik ihtiyaçlarını da karşılamaktadırlar (Akay, 2003).

Önceleri lüks ürün grubunda yer alan otomobiller günümüzde neredeyse zorunlu ürün haline gelmiştir. Bunun temel sebeplerden birisi, günümüz şehirleşme koşullarıdır (Zhang ve ark., 2018). Büyük şehirlerde çalışma hayatındaki hızlı gelişim ve uzak mesafe gibi nedenlerle kişiler kimi zaman toplu taşıma yerine otomobile yönelmektedir. Otomobilin zaman içerisindeki gelişimi incelendiğinde, icadından bu yana birçok yönüyle değişime uğramıştır. Bu değişim sadece teknoloji yönüyle değil, donanımdaki değişim nedeniyle artık bireyler için bir tutku olma özelliği göstermektedir. Öyle ki artık otomobil, sahibinin kişiliği hakkında bilgi verecek kadar hayatın içine müdahil olmuştur. Çünkü günümüzde tüketiciler kendi kişilik özelliklerini en iyi yansıtan otomobillere yönelmektedir (Dinç, 2010).

Tüketiciler otomobillerden çeşitli amaçlarla yararlanmak ve kullanmak, yenilik, prestij, gösteriş ve statü kazanmak gibi sebeplerle otomobil sahibi olmak isterler. Otomobili özgürlük ve yaşam kolaylığı olarak algılayanların da sayısı az değildir (Arslan, 2003).

Yapılan literatür taramasına göre bireylerin otomobil tercihi üzerinde çeşitli faktörlerin etkili oldukları ilgili araştırmacılar tarafından bildirilmiştir. Kişisel (demografik) faktörler (Bayraktar, 2004; Zengin, 2012; Aktuğlu ve Temel, 2006), psikolojik faktörler (Türkay, 2011; Fettahlığlu, 2008), sosyal faktörler (Ak, 2009; Zengin, 2012) bunlardan bazılarıdır. Uluslararası literatürde, son zamanlarda tüketicilerin otomobil tercihinde etkili olan iletişim kanalları üzerine çeşitli çalışmalar yapılmıştır (Rijnsoever ve ark., 2009; Rijnsoever ve ark., 2012; Kulkarni ve ark., 2012; Jun Park ve Yeom, 2014).

Türkiye'de 2021 yılı Mart ayında toplam motorlu taşıt sayısı 24454396 iken bu rakamın 12293 727'si (\%54.36) yani yarıdan fazlası otomobillerdir (TÜİK, 2021b). 2021 yılı ilk 4 ay içinde 68302 adet ölümlü ve yaralamalı trafik kaza sayısının 33589'u (\%49.18) yani yarıya yakını otomobillere aittir (EGM, 2021). Buradan otomobillerin trafikte gerek taşıt sayısı gerekse trafik kazası bakımından önemli bir yere sahip olduğu anlaşılmaktadır. İnsanların günlük yaşantısında da otomobil sahibi olmanın ne kadar önemli olduğu ortaya çıkmaktadır.

$\mathrm{Bu}$ çalışmada bireylerin otomobil sahibi olmasını etkileyen faktörlerin çoklu regresyon modeli ve alternatif regresyon modelleriyle (Ridge, Lasso ve Elastic-Net regresyon modelleri) incelenmesi ve önemli faktörlerin belirlenmesi amaçlanmıştır.

\section{MATERYAL VE YÖNTEM}

\subsection{Materyal}

Çalışmada kullanılan veriler Türkiyeİstatistik Kurumu (TÜİK)'nun www.tuik.gov.tr web sitesinde bulunan Tablo 1'de sunulan değişkenlere aittir. 1000 kişi başına düşen otomobil sayısı verileri https:/ / biruni.tuik.gov. $\operatorname{tr} /$ medas $/$ ?kn=89\&locale=tr web sitesinden, TÜFE (Tüketici fiyat indeksi) verileri https://biruni.tuik. gov.tr/medas/?kn=84\&locale=tr web sitesinden, il ve devlet karayolu Karayolları Genel Müdürlüğü'nün www.kgm.gov.tr web sitesinden alınmıştır. Kişi başına Gayri Safi Yurt İçi Hasıla (GSYİH) ve dolar kuru Dünya Bankası'na ait https://www.yillaragore. com/yillara-gore-gayrisafi-milli-hasila-gsmh/ web adresinden alınmıştır. Türkiye'de 2007-2020 yılları arasındaki değişkenlerin (x1, x2, x3, x4 ve x5) otomobil sahipliğini etkileyen faktörler araştırılmıştır. Verilerin regresyon analizi R programı ile yapılmıştır. R Studio programı içinde "glmnet" paketi kullanılmıştır. 
Tablo 1. Türkiye'de 2007-2020 yıları arası otomobil sahipliği, nüfus, TÜFE, karayolu uzunluğu, GSYİH ve dolar kuru değerleri

\begin{tabular}{|l|c|c|c|c|c|c|}
\hline Y1llar & $\mathrm{y}$ & $\mathrm{x} 1$ & $\mathrm{x} 2$ & $\mathrm{x} 3$ & $\mathrm{x} 4$ & $\mathrm{x} 5$ \\
\hline 2007 & 92 & 70586256 & 145.77 & 61912 & 9656 & 1.17 \\
\hline 2008 & 95 & 71517100 & 160.44 & 62023 & 10931 & 1.52 \\
\hline 2009 & 98 & 72561312 & 170.91 & 62219 & 8980 & 1.51 \\
\hline 2010 & 102 & 73722988 & 181.85 & 62785 & 10560 & 1.55 \\
\hline 2011 & 109 & 74724269 & 200.85 & 62930 & 11205 & 1.92 \\
\hline 2012 & 114 & 75627384 & 213.23 & 63255 & 11588 & 1.79 \\
\hline 2013 & 121 & 76667864 & 229.01 & 63496 & 12480 & 2.14 \\
\hline 2014 & 127 & 77695904 & 247.72 & 63754 & 12112 & 2.32 \\
\hline 2015 & 134 & 78741053 & 269.54 & 64278 & 11019 & 2.91 \\
\hline 2016 & 142 & 79814871 & 292.54 & 64619 & 10833 & 3.54 \\
\hline 2017 & 149 & 80810525 & 327.41 & 64962 & 10616 & 3.82 \\
\hline 2018 & 151 & 82003882 & 393.88 & 65174 & 9693 & 5.27 \\
\hline 2019 & 150 & 83154997 & 440.5 & 65171 & 9492 & 5.95 \\
\hline 2020 & 157 & 83614362 & 504.81 & 65110 & 7604 & 7.35 \\
\hline
\end{tabular}

y: 1000 kişiye düşen otomobil sayısı, x1: Nüfus, x2: TÜFE, x3: İl ve devlet karayolu uzunluğu, x4: Kişi başına GSYIH (\$), x5: Dolar kuru.

Bağımlı değişken: y: 1000 kişiye düşen otomobil sayısı, Bağımsız değişkenler: Diğer tüm değişkenlerdir (x1, $x 2, x 3, x 4$ ve $x 5)$.

\section{Yöntem}

\section{Çoklu doğrusal regresyon yöntemi}

$$
y=\beta_{0}+\beta_{1} x_{1}+\beta_{2} x_{2}+\cdots+\beta_{p} x_{p}+\varepsilon
$$

şeklindedir. Burada $\beta_{0}, \beta_{1}, \beta_{2}, \ldots, \beta_{p}$ regresyon modeline ait kısmı regresyon katsayılarıdır. Parametre tahminleri en küçük kareler yöntemi ile belirlenir (Chatterjee ve Hadi, 2012). Çoklu regresyon analizinde hata terimlerinin bağımsızlığı, hata terimlerinin ortalamasının sıfır, sabit varyanslı ve normal dağılıma sahip olması gerekir (Myers, 1986). Bağımsız değişkenler arasında çoklu doğrusal bağlantı olmaması bir diğer önemli varsayımdır. Çoklu bağlantı olma durumu varyans büyültme faktörü (VIF) ile tespit edilir. VIF $\geq 10$ ise çoklu bağlantı sorunu meydana gelir. VIF değeri aşağıdaki gibi hesaplanır (Chatterjee ve Hadi, 2012).

$$
V I F_{i}=\frac{1}{1-R_{i}^{2}}, i=1,2, \ldots, s
$$

VIF formülünde ifade edilen $s$ ise bağımsız değişken sayısıdır. Kaç tane bağımsız değişken varsa o kadar VIF değeri hesaplanabilir.

Burada değeri bağımsız değişkenler arasındaki belirlilik katsayısıdır. Çoklu bağlantı olması durumunda Ridge, Lasso ve Elastic-Net regresyon yöntemleri incelenebilir (Bulut, 2018).

Ridge regresyon yöntemi, en küçük kareler (EKK) yöntemine benzer bir yöntemle çözümlenir. Ridge regresyon yönteminde, regresyon katsayı tahminlerini hesaplamadan önce standart formdaki değişkenlerin oluşturdukları ( $\left.X^{\prime} X\right)$ matrisinin köşegen elemanlarına küçük ve pozitif bir sabitin eklenmesiyle gerçekleştirilir. Buna göre Ridge regresyon çözümü

$\hat{\beta}=\left(X^{\prime} X+\lambda I\right)^{-1} X^{\prime} Y$

şeklindedir.

Bağımsız değişkenler korelasyon matrisinin köşegen elemanlarına pozitif sabitlerin eklenmesindeki amaç, matris şartlı sayısının önemli ölçüde küçültülmesidir. için ridge çözümü en küçük kareler çözümüne eşdeğer olduğundan ridge tahmini, EKK tahmininin bir doğrusal dönüşümüdür (Sakallığlu ve Kaçıranlar, 2008).

Optimum değerinin seçilmesinde genelde ridge regresyonunun grafiksel gösterimi olan ridge izi ve varyans büyültme değerlerinden faydalanılır. Ridge izinde nın bir fonksiyonu gibi regresyon katsayıları gösterilir ve düşey eksene regresyon katsayıları yatay eksene ise değerleri yazılarak oluşturulan grafikte katsayıların stabil olduğu değeri seçilir. VIF değerine göre genelde $\mathrm{VIF}<10$ olduğunda nın alacağı değer seçilir (Marquardt ve Snee, 1975).

Tibshirani (1996) En Küçük Mutlak Büzülme ve Operatör Seçimini (LASSO, Least Absolute Shrinkage and Selection Operator);

$\sum_{\substack{i=1 \\ \text { koşulu ile }}}^{p}\left|\beta_{i}\right| \leq t$

$$
\min _{\beta}(y-x \beta)^{\prime}(y-x \beta)
$$

olarak ifade etmiştir. Burada t parametresi, tahminlere uygulanan büzülmenin miktarını kontrol eder. Lasso, EKK tahmin edicisi $\hat{\beta}_{E K K}$ 'yi sıfıra büzebilir ve bazı $\mathrm{i}$ değerleri için $\hat{\beta}_{i}=0$ olabilir.

LASSO regresyonda EKK yöntemine benzer şekilde $\beta$ katsayılarının elde edilmesi için kullanılan yanlılık sabitinin de modele dâhil edilmesiyle elde edilen eşitlik aşağıdaki gibi ifade edilir. Bu LASSO ile regresyon katsayılarının hesaplanması için kullanılan Lagrangian formdur.

$\hat{\beta}_{\text {lasso }}=\arg \min \left\{\sum_{i=1}^{n}\left(y_{i}-\beta_{0}-\sum_{i=1}^{p} x_{i j} \beta_{j}\right)^{2}+\lambda \sum_{j=1}^{p}\left|\beta_{j}\right|\right\}$

Burada, $l_{1}=\sum_{j=1}^{p}\left|\beta_{j}\right|$ ceza fonksiyonudur, ise pozitif bir değer olup, ceza parametresidir ve büzülme miktarını kontrol eder. LASSO regresyonu analiz 
etmek için quadratik programlama gerekir (Hastie ve ark., 2007)

Elastic Net yöntemi, LASSO yönteminin bir takım limitasyonlarını engellemek için ortaya çıkmıştır. LASSO, birbiriilekorelasyonu yüksekparametrelerden sadece birini seçerek diğerlerini gözardı eder. Bu yüzden Elastic Net, LASSO düzenleştiriciyle beraber Ridge düzenleştiricisini de kullanır.

Elastic-Net tahmincisi,

$$
\hat{\beta}_{\text {Elastic-Net }}=\arg \min \left\{\sum_{i=1}^{n}\left(y_{i}-x_{i}^{\prime} \beta\right)^{2}+\lambda_{1} \sum_{j=1}^{p} \beta_{j}^{2}+\lambda_{2} \sum_{j=1}^{p}\left|\beta_{j}\right|\right\}
$$

olarak hesaplanır (Zou ve Hastie, 2005).

\section{BULGULAR VE TARTIŞMA}

Bağımlı değişken olan 1000 kişiye düşen otomobil sayısını etkileyen faktörlerin etkisi regresyon analizi ile incelenmiştir. Bu faktörler nüfus, TÜFE, il ve devlet karayolu uzunluğu, kişi başına GSYIH ve dolar kurudur. Önce çoklu regresyon modeli incelenmiştir. Çoklu regresyon modeli parametre katsayıları Tablo 2'de verilmiştir.

Tablo 2'de görüldüğü gibi sabit terim dişında tüm bağımsız değişkenlerin katsayıları istatistiksel olarak önemsiz çıkmıştır. Modelin R2 değeri 0.99 bulunmuştur. Çoklu regresyon modelinde tüm değişkenlerin parametre katsayıların önemli olması gerekir. Ayrıca değişen varyanslılık, otokorelasyon ve çoklu bağlantı gibi sorunların olmaması gerekir. Çoklu bağlantı sorunu varyans büyültme faktörü (VIF) ile incelenir. Tablo 2'de verilen VIF değerleri $x 4$ yani kişi başına GSYİH değişkeni hariç tüm değişkenler 10'dan büyüktür. VIF>10 olması çoklu bağlantı sorunu olduğunu ortaya koyar. Çoklu bağlantı sorununu gidermek için Ridge regresyon, Lasso regresyon ve Elastic-Net regresyon modelleri denenmiştir.

Ridge regresyon yöntemi ile sonuca ulaşmak için önce Ridge tahmin edicisi olan

$$
\hat{\beta}=\left(X^{\prime} X+\lambda I\right)^{-1} X^{\prime} Y
$$

değerini hesaplamak için en uygun $\lambda$ değerinin seçilmesidir. $\mathrm{Bu}$ nedenle Ridge izi yöntemini kullanarak parametre tahminlerinin daha kararlı olacağ1 optimal bir $\lambda$ noktası seçilir. $\lambda$ değerinin alabileceği en küçük değeri vermekte olup, default değeri 0.01 'dir. $\lambda$ 'nın en iyi sonucu verdiği yani en düşük Hata Kareler Ortalamasının (HKO) elde edildiği aralık $\mathrm{R}$ programinda (plot(bestlambda)) komutu ile yapılmıştır. Analiz sonucunda en küçük HKO değerini veren $\lambda=1.103731^{\prime \prime}$ dir (Şekil 1).

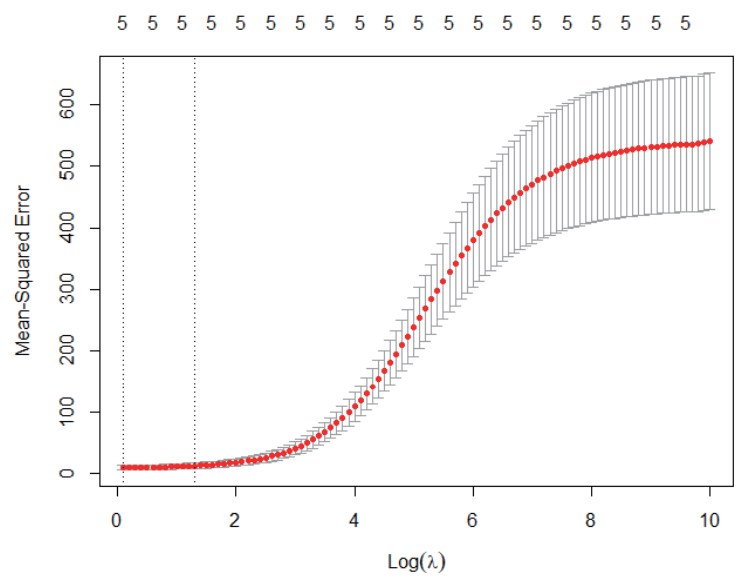

Şekil 1. Ridge regresyonda $\lambda$ 'nın değerini belirleyen çapraz geçerlilik incelemesi

$\lambda=1.103731$ için oluşturulan Ridge regresyon modeline ait parametre katsayıları Tablo 3'te verilmiştir.

Tablo 3. Ridge regresyon modeli parametre katsayıları

\begin{tabular}{lllll}
\hline Parametreler Tahminler & Std. hata & t değeri & P \\
\hline (Intercept) & $-5.986900 .10^{\wedge} 2$ & $2.325 .10^{\wedge} 2$ & -2.575 & $0.029^{*}$ \\
x1 & $1.763914 .10^{\wedge}-6$ & $0.824 .10^{\wedge}-6$ & 2.141 & $0.043^{*}$ \\
x2 & $2.396763 .10^{\wedge}-2$ & $1.278 .10^{\wedge}-2$ & 1.876 & 0.098 \\
×3 & $8.910543 .10^{\wedge}-3$ & $3.338 .10^{\wedge}-3$ & 2.673 & $0.014^{*}$ \\
x4 & $8.830093 .10^{\wedge}-4$ & $7.257 .10^{\wedge}-4$ & 1.217 & 0.189 \\
x5 & 1.165974 & 0.419 & 2.783 & $0.021^{*}$ \\
\hline${ }^{* * *}: p<0.001,{ }^{* *}: p<0.01, *: p<0.05$ & & &
\end{tabular}

Tablo 3'te görüldüğü gibi $\lambda=1.103731$ 'e göre elde edilen Ridge regresyon modeli, $y=-598.69+0.00000176 \times 1+0.0239676 \times 2+0.00891 \times 3$
$+0.000883 \times 4+1.166 \times 5$ şeklindedir. Modele ait
HKO=6.044 olarak bulunmuştur.

Ridge regresyonda olduğu gibi Lasso regresyon analizinde ilk olarak $\lambda$ değeri hesaplanır. Çapraz geçerlilik ile belirlenecek en küçük değerini verecek

Tablo 2. Çoklu regresyon modeli parametre katsayıları

\begin{tabular}{lrrrrr}
\hline Parametreler & & & & \\
& Tahminler & Std. hata & $\mathrm{t}$ değer & $\mathrm{P}$ & VIF \\
\hline (Intercept) & $-8.384 .10^{\wedge} 2$ & $2.378 .10^{\wedge} 2$ & -3.526 & $0.00778 * *$ & \\
x1 & $1.674 .10^{\wedge-6}$ & $3.106 .10^{\wedge}-6$ & 0.539 & 0.60450 & 309.229 \\
X2 & $-6.978 .10^{\wedge-2}$ & $1.464 .10^{\wedge}-1$ & -0.477 & 0.64644 & 452.842 \\
X3 & $1.315 .10^{\wedge}-2$ & $6.905 .10^{\wedge}-3$ & 1.905 & 0.09330 & 120.466 \\
x4 & $1.749 .10^{\wedge}-4$ & $1.258 .10^{\wedge}-3$ & 0.139 & 0.89288 & 4.606 \\
x5 & 4.177 & 6.416 & 0.651 & 0.53331 & 259.872 \\
\hline$* * *: p<0.001, * *: p<0.01, *: p<0.05$ & & &
\end{tabular}


default değeri $0.01^{\prime}$ dir. $\lambda$ 'nin en iyi sonucu verdiği yani en küçük HKO değerini veren aralık Şekil 2'de sunulmuştur.

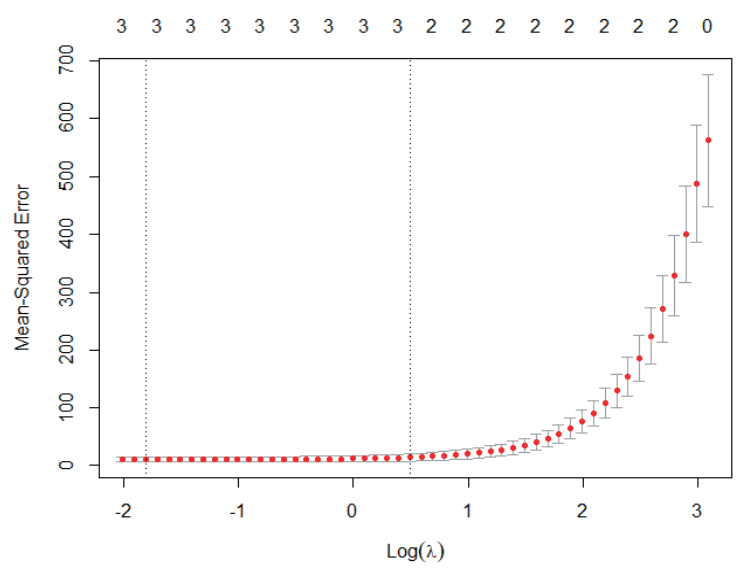

Şekil 2. Lasso regresyonda $\lambda$ 'nın değerini belirleyen çapraz geçerlilik incelemesi

Hesaplanan en iyi lambda değeri $\lambda=0.164097$ 'dir. Bu $\lambda=0.164097$ değeri kullanılarak elde edilen Lasso katsayılarını kapsayan model Tablo 4'de verilmiştir.

Tablo 4. Lasso regresyon modeli parametreleri

\begin{tabular}{|c|c|c|c|c|}
\hline Parametreler & Tahminler & Std. hata & $t$ değeri & $\mathrm{P}$ \\
\hline $\begin{array}{l}\text { (Intercept) } \\
\times 1 \\
\times 2\end{array}$ & $\begin{array}{c}-8.469439 .10^{\wedge} 2 \\
1.043496 .10^{\wedge}-6\end{array}$ & $\begin{array}{l}2.176 .10^{\wedge} 2 \\
0.235 .10^{\wedge}-6\end{array}$ & $\begin{array}{c}-3.892 \\
4.438\end{array}$ & $\begin{array}{l}0.0081 * * \\
0.0062 * *\end{array}$ \\
\hline $\begin{array}{l}x 2 \\
\times 3\end{array}$ & i. $394275.10^{\wedge}-2$ & $0.289 .10^{\wedge}-2$ & 4.823 & $0.0053 * *$ \\
\hline $\begin{array}{l}44 \\
\times 5\end{array}$ & $8.735862 .10^{\wedge}-1$ & $1.412 .10^{\wedge}-1$ & 6.187 & $0.0031 * *$ \\
\hline
\end{tabular}

Lasso regresyon modeline ait $\mathrm{HKO}=4.461$ olarak hesaplanmıştır.

Elastic-Net regresyon analizinde ilk olarak $\lambda$ değeri hesaplanır. Çapraz geçerlilik ile belirlenecek en küçük değerini $\lambda$ verecek default değeri $0.01^{\prime}$ dir. $\lambda$ 'nin en iyi sonucu verdiği yani en küçük HKO değerini veren aralık Şekil 3'te sunulmuştur.

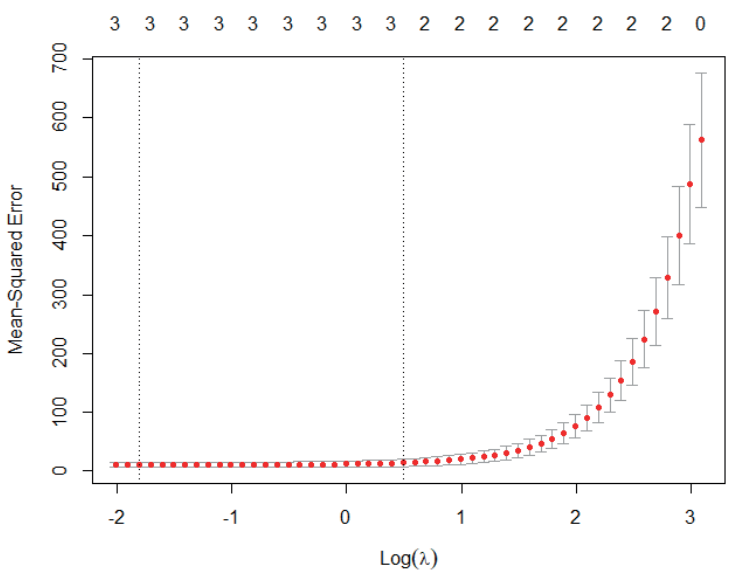

Şekil 3. Elastic-Net regresyonda $\lambda$ 'nın değerini belirleyen çapraz geçerlilik incelemesi
Hesaplanan en iyi lambda değeri $\lambda=0.557763^{\prime \prime}$ dir. $\mathrm{Bu} \lambda$ değeri kullanılarak elde edilen Elastic-Net katsayıları Tablo 5'te verilmiştir.

Tablo 5. Elastic-Net regresyon modeli parametreleri

\begin{tabular}{|c|c|c|c|c|}
\hline Parametrele & Tahminler & std. hata & t değeri & $P$ \\
\hline $\begin{array}{l}\text { (Intercept) } \\
x_{1}\end{array}$ & $\begin{array}{r}-8.221001 .10^{\wedge} 2 \\
1.199755 .10^{\wedge}-6\end{array}$ & $\begin{array}{l}2.156 \cdot 10^{\wedge} 2 \\
0.371 .10^{\wedge}-6\end{array}$ & $\begin{array}{r}-3.813 \\
3.235\end{array}$ & $\begin{array}{l}0.0034 \% * * \\
0.0027^{* * *}\end{array}$ \\
\hline $\begin{array}{l}x 2 \\
x 3\end{array}$ & i. $337080.10^{\wedge}-5$ & $0.476 .10^{\wedge}-5$ & 2.809 & $0.0107 *$ \\
\hline $\begin{array}{l}x+4 \\
\times 5\end{array}$ & $\dot{7} .155408 .10^{\wedge}-1$ & $2.113 .10^{\wedge}-1$ & 3.386 & $0.0029 * *$ \\
\hline
\end{tabular}

Elastic-Net regresyon modeline ait $\mathrm{HKO}=4.655$ olarak hesaplanmıştır.

Ridge, Lasso ve Elastic-Net regresyon modelleri arasında tercih yapmak için HKO, R2 ve $\bar{R}^{2}$ değerleri dikkate alınmıştır ve Tablo 6'da verilmiştir.

Tablo 6. Regresyon modellerine ait HKO değerleri

\begin{tabular}{|l|c|c|c|}
\hline Yöntem & HKO & $\mathrm{R}^{2}$ & $\bar{R}^{2}$ \\
\hline Ridge regresyon & 6.044 & 0.953 & 0.932 \\
\hline Lasso regresyon & 4.461 & 0.976 & 0.972 \\
\hline Elastic-Net regresyon & 4.655 & 0.952 & 0.943 \\
\hline
\end{tabular}

Tablo 6'da verilen sonuçlara göre en küçük HKO değerine ve en büyük $\mathrm{R}^{2}, \bar{R}^{2}$ değerlerine sahip olan regresyon yöntemi Lasso regresyondur. Elastic-net regresyon yönteminin de Lasso regresyona yakın bir başarı sağladığı görülmüştür. Bu çalışmada Ridge regresyon ise göreli olarak Lasso ve Elastic-Net analizlerinin gerisinde kalmıştır. Dolayısıyla en uygun bulunan Lasso regresyon modeli değerlendirildiğinde, Tablo 4'te verilen model parametrelerinden x2 (TÜFE) ve x4 (GSYİH) değişkenleri modele alınmamış ve bu değişkenler önemsiz bulunmuştur. Kisaca 1000 kişiye düşen otomobil sayısını etkileyen önemli faktörler nüfus, il ve devlet karayolu uzunluğu ile dolar kuru olmuştur. En büyük katsayıya sahip olan değişken x5 (dolar kuru) olduğundan, otomobil sahipliğini en fazla etkileyen faktör olduğu söylenebilir. Bunu sırasıyla x3 (karayolu uzunluğu) ve x1 (nüfus) gibi faktörler izlemektedir. Önemli değişkenlerin katsayı değerleri yaklaşık sırasıyla x5 için 0.8735862, x3 için 0.01394275 , x1 için 0.000001043496 ve sabit terim için -846.9439 olarak hesaplanmıştır. Genel olarak Ridge regresyon çoklu bağlantı durumunda, Lasso regresyon ise yüksek boyutsal veri durumunda yani bağımsız değişken sayısı gözlem sayısından fazla olduğunda faydalı sonuçlar vermektedir. Elastic-Net regresyonu ise her iki durumda da iyi sonuçlar vermektedir.

Ridge, Lassso ve Elastic-Net regresyon yöntemleri ile çeşitli alanlarda yapılan çalışmaların birinde, Japon bıldırcını yumurtasında iç kalite özelliklerinin tahmini 
yapılmıştır (Çiftsüren ve Akkol, 2018). Yumurta sarısı ağırlığı ve yumurta akı ağırlığını tahmin etmede Lasso regresyonunun diğerlerinden daha iyi uyum iyiliği istatistiğine sahip olduğu ortaya çıkmıştır. Bir diğer çalışmada, sermeye yeterliliğini etkileyen bilanço yapısı, aktif kalitesi, likidite, karlılık, gelir-gider yapısı ve sektör payları gibi faktörler incelenmiştir. Çoklu bağlantı olduğu saptandığından Elastic-Net regresyonu uygulanmıştır (Rençber ve Bağc1, 2019).

\section{SONUÇ}

Çoklu bağlantı, çoklu doğrusal regresyon yönteminde yaygın olarak görülen önemli sorunlardan biridir. $\mathrm{Bu}$ sorunu gidermeye çalışan çeşitli yöntemler bulunmaktadır. Ridge, Lasso ve Elastic-Net regresyon yöntemleri bu yöntemler arasındadır. Bu çalışmada, kullanılan çoklu regresyon modelinde çoklu bağlantı sorunu görüldüğünden söz konusu alternatif regresyon yöntemleri kullanılmıştır. $\mathrm{Bu}$ alternatif yöntemlerden en iyi sonucu Lasso regresyon yöntemi vermiştir. Lasso regresyon yöntemi en düşük $\mathrm{HKO}=4.461$ ve en yüksek $\mathrm{R}^{2}=0.976$ değerine sahiptir. Kişilerin otomobil sahipliğini en yüksek düzeyde dolar kuru etkilemiştir. Karayolu (il ve devlet yolu) uzunluğu ve nüfus etkeni otomobil sahipliğini etkileyen diğer önemli etkenlerdir. İleride yapılacak çalışmalarda, çoklu doğrusal regresyon yönteminin gerekli tüm varsayımları sağlayamaması durumunda Ridge, Lasso ve Elastic-Net regresyon yöntemi gibi alternatif regresyon yöntemlerinin birçok alanda kullanımının uygun olacağ 1 ve literatüre katkı sağlayacağı umulmaktadır.

\section{KAYNAKÇA}

AK, T. (2009). Marka yönetimi ve tüketici karar sürecine etkileri. Yayınlanmış Yüksek Lisans Tezi, Karamanoğlu Mehmet Bey Üniversitesi, Karaman.

AKAY, A. (2003). Otomobil pazarında tüketici davranışları: Satın alma kararlarını etkileyen faktörlerin tespitine yönelik Ampirik bir çalışma. Ankara Üniversitesi Sosyal Bilimler Enstitüsü, yayınlanmış yüksek lisans tezi, Ankara.

AKTUĞLU I. K., TEMEL, A. (2006). Tüketiciler markaları nasıl tercih ediyor? (Kamu sektörü çalışanlarının giysi markalarını tercihini etkileyen faktörlere yönelik bir araştırma). Konya Selçuk Üniversitesi Sosyal Bilimler Enstitüsü Dergisi, 15, 43-59.
ANONIM, (2020). Yıllara Göre Gayrisafi Milli Hasıla - GSMH. https://www.yillaragore.com/yillara-gore-gayrisafi-milli-hasilagsmh/ (Erişim tarihi: 12.04.2021).

ARSLAN, K. (2003). Otomobil alımında tüketici davranışlarını etkileyen faktörler. İstanbul Ticaret Üniversitesi Dergisi, 2(3), 83103.

BAYRAKTAR, B. (2004). Otomobil sektöründe uygulanan önemli demografik bölümlendirme kriterleri (Genel bir bakış). Balıkesir Üniversitesi Sosyal Bilimler Enstitüsü Dergisi, 7(11), 1-10.

BULUT, H. (2018). R Uygulamaları ile Çok Değişkenli İstatistiksel Yöntemler. Nobel Akademik Yayıncılık, Ankara.

CHATTERJEE, S., HADİ, A. S. (2012). Regression Analysis by Example. Wiley Series in Probability and Statistics. John Wiley and Sons, Canada.

ÇIFTSÜREN, M. N., AKKOL, S. (2018). Prediction of internal egg quality characteristics and variable selection using regularization methods: ridge, LASSO and elastic net. Arch. Anim. Breed., 61, 279-284

DİNÇ, Y. (2010). Konjoint analizi ve otomobil seçim kriterleri üzerine bir uygulama. Marmara Üniversitesi Basılmamış Yüksek Lisans Tezi, Sosyal Bilimler Enstitüsü, İstanbul.

EGM, (2021). Trafik İstatistik Bülteni Nisan 2021. Emniyet Genel Müdürlüğü Trafik Başkanlığı.

FETTAHLIOĞLU, H. S. (2008). Tüketicilerin satın alma davranışlarında özel markaların tüketici tutumları üzerine etkileri. Doktora Tezi, Dokuz Eylül Üniversitesi: İzmir.

HASTIE, T., TAYLOR, J., TIBBSHIRANİ, R., WALTHER, G. (2007). Forward stagewise regression and the monotone lasso. Electronic Journal of Statistics, 1, 1-29

JUN, S.P., PARK, D. H., YEOM, J. (2014). The possibility of using search traffic information to explore consumer product attitudes and forecast consumer preference. Technological Forecasting and Social Change, 86, 237-253.

KGM, (2020). Karayolları Genel Müdürlüğü. Devlet ve il yolları envanteri.https://www.kgm.gov.tr/SiteCollectionDocuments/ KGMdocuments/Istatistikler/DevletIlYolEnvanter/ YillaraGoreDevletVeIlYollari.pdf (Erişim tarihi:02.04.2021).

KULKARNI, G., RATCHFORD, B. T., KANNAN, P. K. (2012). The impact of online and offline information sources on automobile choice behavior. Journal of Interactive Marketing, 26, 167-175.

MARQUARDT, D. W., SNEE, R. D. (1975). Ridge Regression in Pratice. The American Statistician, February 1975, Vol. 29, p3-20.

MYERS, R. H. 1986. Classical and modern regression with 
applications, 2nd ed., Duxbury Press, California.

RIJNSOEVER, F. J. V., CASTALDI, C., DIJST, M. J. (2012). In What Sequence Are Information Sources Consulted By Involved Consumers? The Case of Automobile Pre- Purchase Search, Journal of Retailing and Consumer Services 19, 343-352.

RIJNSOEVER, F. V., FARLA, J., DIJST, M. J. (2009). Consumer Car Preferences and Information Search Channels. Transportation Research, Part D, 14, 334-342.

SAKALLIOĞLU, S., KAÇIRANLAR, S. 2008. A new biased estimator based on ridge estimation. Statistical Papers, 49, 669-689.

R Core Team. 2019. R: A language and environment for statistical computing. R Foundation for Statistical Computing, $\mathrm{R}$ version: 3.6.2. Vienna, Austria. URL: https://www.R- project. org/.

RENÇBER, Ö. F., BAĞCI, H. (2019). Determination of factors affecting capital adequacy using the elastic net regression method.

OPUS-International Journal of Society Researches, 11(18), 1828-1844. DOI: 10.26466/opus.561915

TIBBSHIRANI, R. (1996). Regression Shrinkage and Selection Via The LASSO, J. Roy. Statist. Soc., Ser. B, 58:267-288.

TÜİK, (2020). Ulaştırma İstatistikleri. Bin kişi başına otomobil sayısı https://biruni.tuik.gov.tr/medas/?kn=89\&locale=tr (Erişim tarihi: 22.04.2021).

TÜIKK, (2021ª). Adrese dayalı nüfus kayıt sistemi sonuçları, 2020. Türkiye İstatistik Kurumu Haber Bülteni, Sayı:37210. https://data. tuik.gov.tr/Bulten/Index?p=Adrese-Dayali- Nufus-Kayit-SistemiSonuclari-2020-37210(Erişim tarihi:11.04.2021).

TÜİK, (2021b). Motorlu Kara taşıtları Mart 2021. Türkiye İstatistik Kurumu. https://data.tuik.gov.tr/Kategori/ GetKategori?p=ulastirma-ve-haberlesme-112\&dil=1.

TÜİK, (2021c). Tüketici Fiyat İndeksi. https://biruni.tuik.gov.tr/ medas $/$ ?kn=84\&locale=tr (Erişim tarihi:06.04.2021).

TÜRKAY, A. (2011). Satın alma davranışları açısından üniversite öğrencileri arasında marka bağımlılığının önemi: Batı Akdeniz Üniversiteleri üzerinde bir uygulama. Yayınlanmamış Yüksek Lisans Tezi, Süleyman Demirel Üniversitesi: Isparta.

YAYAR, R., ÇOBAN, M. N., TEKİN, B. (2015). Otomobil Sahipliğini Etkileyen Faktörlerin Belirlenmesi: Tokat İli Kentsel Alanda Bir Uygulama. Yönetim ve Ekonomi, 22(2), 603-617.

ZENGIN, S. (2012). Markanın tüketici davranışlarına etkisi ve otomotiv sektörü üzerine bir uygulama. Yayınlanmış Yüksek Lisans Tezi, Adıyaman Üniversitesi: Adıyaman.

ZHANG, Y., Lİ, C., LİU, Q. E., WU, W. (2018). The socioeconomic characteristics, urban built environment and household car ownership in a rapidly growing city: Evidence from Zhongshan, China. Journal of Asian Architecture and Building Engineering, 17(1), 133-140.

ZOU, H., HASTIE, T. (2005). Regularization and variable selection via the elastic net. Journal of the Royal Statistical Society. Series B: Statistical Methodology 67(2), 301-320. 